\title{
Molecular Cytogenetic Search for Cryptic Sex Chromosomes in Painted Turtles Chrysemys picta
}

\author{
Nicole Valenzuela Daleen Badenhorst Eugenia E. Montiel Robert Literman
}

Department of Ecology, Evolution, and Organismal Biology, lowa State University, Ames, lowa, USA

\section{Key Words}

Comparative genome hybridization - Chrysemys picta turtle genome $\cdot$ Environmental sex determination - Evolution of sex chromosomes - Genotypic sex determination .

Heritability and maternal effects $\cdot \mathrm{H}-\mathrm{Y}$ antigens .

Temperature-dependent sex determination

\begin{abstract}
Sex determination is triggered by factors ranging from genotypic (GSD) to environmental (ESD), or both GSD + EE (GSD susceptible to environmental effects), and its evolution remains enigmatic. The presence/absence of sex chromosomes purportedly separates species at the ESD end of the continuum from the rest (GSD and GSD + EE) because the evolutionary dynamics of sex chromosomes and autosomes differ. However, studies suggest that turtles with temperature-dependent sex determination (TSD) are cryptically GSD and possess sex chromosomes. Here, we test this hypothesis in painted turtles Chrysemys picta (TSD), using comparativegenome-hybridization (CGH), a technique known to detect morphologically indistinguishable sex chromosomes in other turtles and reptiles. Our results show no evidence for the existence of sex chromosomes in painted turtles. While it remains plausible that cryptic sex chromosomes may exist in
\end{abstract}

TSD turtles that are characterized by minor genetic differences that cannot be detected at the resolution of $\mathrm{CGH}$, previous attempts have failed to identify sex-specific markers. Genomic sequencing should prove useful in providing conclusive evidence in this regard. If such efforts uncover sex chromosomes in TSD turtles, it may reveal the existence of a fundamental constraint for the evolution of a full spectrum of sex determination (from pure GSD to pure TSD) that is predicted theoretically. Finding sex chromosomes in ESD organisms would question whether pure ESD mechanisms exist at all in nature, or whether those systems currently considered pure ESD simply await the characterization of an underlying GSD architecture.

(c) 2014 S. Karger AG, Basel

Sex determination, or the commitment to the developmental male or female fate, is controlled by diverse mechanisms across the tree of life. In animals, sex determination commonly involves a pair of sex chromosomes that differ from each other in one sex (XY males vs. XX females or ZW females vs. ZZ males) [Bachtrog et al., 2011, 2014]. Differences may be morphological due to size or shape (heteromorphic sex chromosomes), or restricted to content (homomorphic sex chromosomes). In some or-

\section{KARGER}

E-Mail karger@karger.com

www.karger.com/cgr
(C) 2014 S. Karger AG, Basel

$1424-8581 / 14 / 1441-0039 \$ 39.50 / 0$
Nicole Valenzuel

Department of Ecology, Evolution, and Organismal Biology Iowa State University

251 Bessey Hall, Ames, IA 50011 (USA)

E-Mail nvalenzu@iastate.edu 
ganisms, the $\mathrm{Y}$ or $\mathrm{W}$ is absent (XO males vs. $\mathrm{XX}$ females or $\mathrm{ZO}$ females vs. ZZ males), and others possess more complex sex chromosome systems [Grützner et al., 2004; Sahara et al., 2012]. In some species, haploid individuals become males and diploids become females, and in others, the zygotic genotype at many loci determines the sexual fate (polyfactorial or polygenic systems) [Bull, 1983]. All of the above are examples of genotypic sex determination (GSD). In contrast, in other organisms, sex is determined by environmental factors experienced after conception (ESD), such as $\mathrm{pH}$, host-size, or temperature (TSD) [Bull, 1983; Valenzuela and Lance, 2004]. Importantly, not all sex-determining mechanisms fall into one of these extremes (GSD vs. ESD), and an increasing number of species are reported with intermediate mechanisms involving both genotypic and environmental influences (GSD + EE sensu Valenzuela et al. [2003]) [Baroiller et al., 1995; Shine et al., 2002; Valenzuela and Lance, 2004; Quinn et al., 2007]. GSD + EE is a GSD mechanism that is susceptible to environmental effects by factors that can cause sex reversal of genotypic males or genotypic females or other types of sex ratio biases [Valenzuela et al., 2003]. The evolution of this diversity has remained an enigma, partly because sex-determining mechanisms are highly conserved in some lineages and quite labile in others, and partly due to the technical difficulty of identifying cryptic homomorphic sex chromosomes.

GSD is ubiquitous in mammals, birds and amphibians, and co-occurs with TSD in fish and reptiles (fig. 1). Species level analyses support TSD as the ancestral state in turtles and squamate reptiles [Pokorná and Kratochvíl, 2009; Valenzuela and Adams, 2011] (but see Organ and Janes [2008] for a family level study), and GSD evolved multiple times in each of these groups. In turtles, each transition of TSD to GSD corresponds to the independent evolutionary gain of sex chromosomes [Valenzuela and Adams, 2011]. Importantly, no turtle is known to possess an intermediate sex-determining mechanism (GSD + EE or TSD + GSD). However, previous research suggests that a genotypic component to sex determination may exist in TSD turtles, perhaps expressed at the pivotal temperature that produces 50:50 sex ratios. This evidence derives from studies of TSD heritability [e.g. Bull et al., 1982; Janzen, 1992; Rhen and Lang, 1998] as well as population genetics and molecular studies where markers appear to segregate by sex in TSD turtles [Engel et al., 1981; Demas et al., 1990; Girondot et al., 1994]. Furthermore, a recent experimental study detected evidence consistent with the existence of an underlying genotypic sex-determining mechanism in the TSD slider turtle Trachemys scripta,

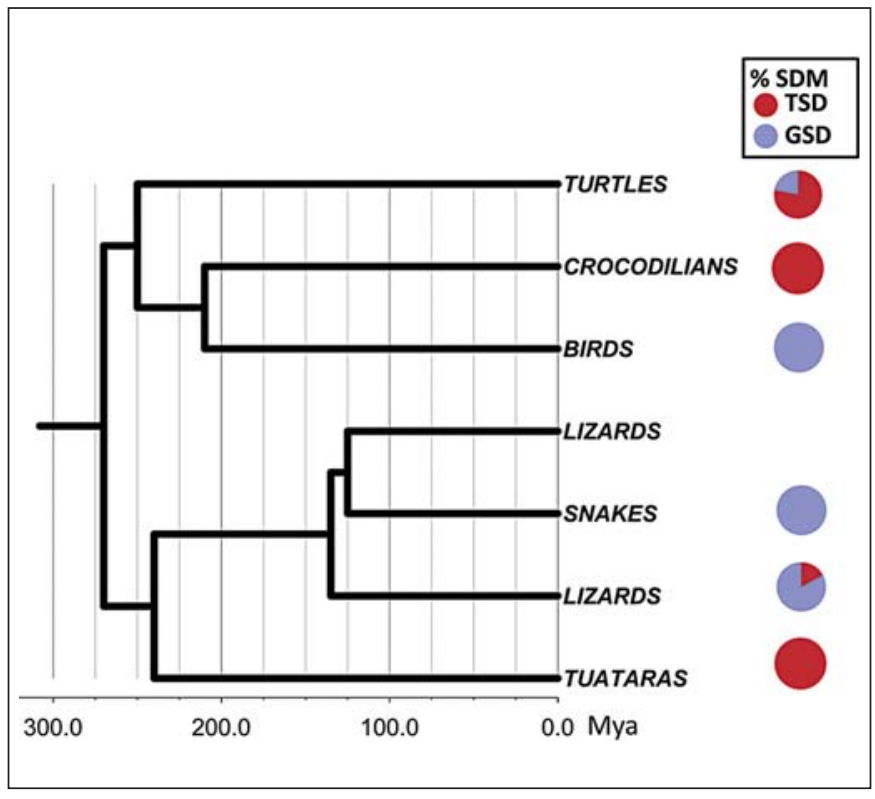

Fig. 1. Phylogenetic relationships and sex-determining mechanisms in reptiles. Topology and divergence times as per Chiari et al. (2012), Jones et al. (2013), and Shaffer et al. (2013). Data on sex determination was collected from the literature [Olmo, 2005; Olmo and Signorino, 2005; Vogt, 2008; Leaché and Sites, 2009; Paez et al., 2009; Pokorná and Kratochvíl, 2009; Shibaike et al., 2009; Bernhard, 2010; Okada et al., 2010; Zhang et al., 2010; Hare et al., 2011; Valenzuela and Adams, 2011; Inamdar et al., 2012; Rojo et al., 2012; Tang et al., 2012; Valenzuela et al., 2013]. Lizards are paraphyletic with snakes nested within this clade. Information on the proportion of TSD/GSD is provided for the totality of lizards combined.

which may be expressed at the pivotal temperature but overridden by higher and lower temperature values [Mork et al., 2014]. Thus, the possibility exists that a cryptic GSD mechanism is present in species previously classified as TSD, which, if true, would require a reclassification of this and potentially many other TSD species as GSD + EE [Valenzuela et al., 2003] and may cause a reevaluation of the evolution of the continuum of sex determination [Valenzuela et al., 2003; Sarre et al., 2004]. One possibility is that cryptic sex chromosomes exist in TSD species that are homomorphic and undetectable by classic cytogenetic techniques but amenable to identification using molecular cytogenetic as in other reptiles [Ezaz et al., 2005, 2006; Martinez et al., 2008; Kawai et al., 2009; Badenhorst et al., 2013].

To address this fundamental issue, we tested empirically whether sex chromosomes are present in the painted turtle Chrysemys picta, a close relative to the slider turtle 
T. scripta, that exhibits a virtually identical pattern of TSD and gene expression [Valenzuela et al., 2013; Mork et al., 2014] and where heritability of the threshold for TSD has also been reported [Rhen and Lang, 1998; McGaugh and Janzen, 2011] consistent with the findings in T. scripta [Mork et al., 2014]. Thus, it would be expected that a GSD mechanism with cryptic sex chromosomes may be present in C. picta as well. We used a molecular cytogenetic approach to examine male and female C. picta to determine whether sex chromosomes are present in this species, in which case C. picta would be reclassified as a GSD + EE taxon. This molecular cytogenetic approach has been used by us and others to detect cryptic sex chromosomes in reptiles [Ezaz et al., 2005, 2006; Martinez et al., 2008; Kawai et al., 2009; Badenhorst et al., 2013]. Here, we discuss the implications of our findings with regards to our current understanding of the evolution of sex determination.

\section{Materials and Methods}

C. picta is a cryptodiran turtle in the family Emydidae with a diploid number of $2 n=50$ (fig. 2) [Killebrew, 1977; De Smet, 1978], the most common chromosome number among turtles [Valenzuela and Adams, 2011]. Thirteen female and 20 male C. picta hatchlings were obtained from eggs incubated at naturally fluctuating temperatures from natural nests or from experimental nests incubated in the field as part of another research project. Briefly, eggs were collected from over 100 nests and randomly distributed among the incubation treatments. Each treatment produced exclusively males or females, indicating that sex reversal was possible if sex chromosomes existed in this species. However, the potential of sex reversal was tested and ruled out by considering all possible scenarios, as explained below (fig. 3). Individual sex was diagnosed by gonadal inspection 3 months post-hatching. All procedures were approved by the Institutional Animal Care and Use Committee of Iowa State University. Cell culture and molecular cytogenetic protocols followed our standard procedures for the detection of cryptic sex chromosomes in turtles [Badenhorst et al., 2013]. In

Fig. 2. Examples of CGH on female (left panels) and male (right panels) C. picta hatchlings showing no sex-specific differential hybridization in any chromosome pair as expected in the absence of sex chromosomes (A-F). Brighter signals are not sexually dimorphic and likely correspond to regions enriched for repetitive elements which are widespread in the painted turtle genome. A and B show male genomic DNA hybridization (red), C and D show female genomic DNA hybridization (green), and $\mathbf{E}$ and $\mathbf{F}$ show the composite image. Chromosomes are counterstained with DAPI (blue). A G-banded karyotype of C. picta is presented in G.
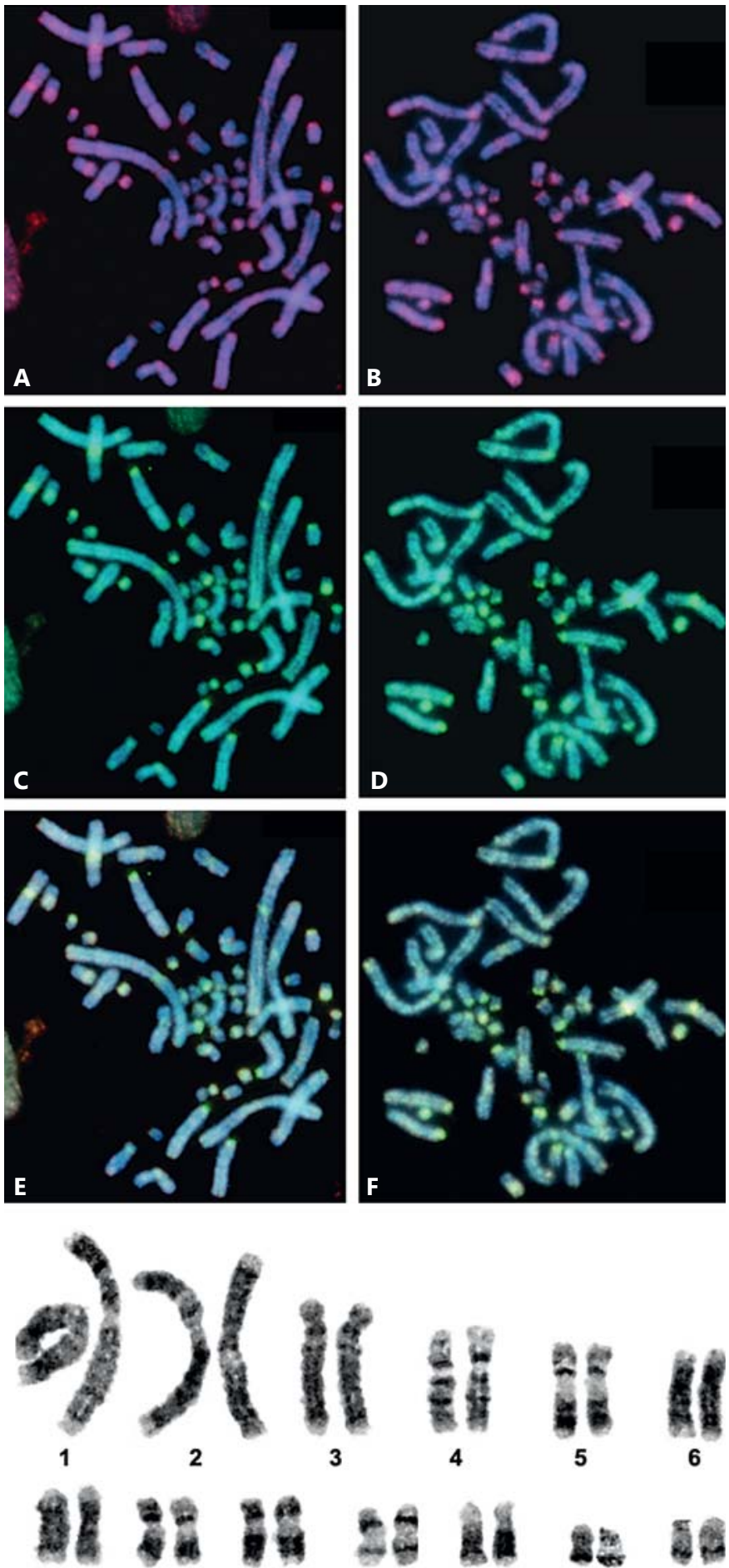

5

6

7

8

9

10

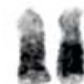

11

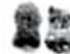

बहल

12

13

$\begin{array}{cc}28 & 48 \\ 14 & 15 \\ 21 & 22\end{array}$

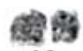

06

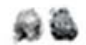

18

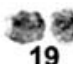

(3) 중

20
No Evidence of Cryptic Sex Chromosomes in TSD Turtles
Cytogenet Genome Res 2014;144:39-46 DOI: $10.1159 / 000366076$ 


\begin{tabular}{|c|c|c|c|c|c|c|}
\hline & & & ASSUMING & HE EXISTENCE OF AN XX/XY SEX CHROMOSC & ME SYSTEM & \\
\hline & & & Cyto \& & & & \\
\hline CASE & CGH DNA & IncTemp & Phenotypic Sex & CGH result & Suggestive of & Interpretation \\
\hline A1 & XX-female-red & Pivotal & $\mathrm{XX}$ female & Uniform yellow & $\mathrm{XX}$ & $\mathrm{XY}$ system - clean \\
\hline & $\mathrm{XY}$-male-green & & $\mathrm{XY}$ male & Male-only green DNA signal on male sample & $\mathrm{XY}$ & SEX CHROMOSOMES ARE CLEARLY SHOWN \\
\hline A2 & XX-female-red & Female-producing & $\mathrm{XX}$ female & Uniform yellow & & Cannot have $\mathrm{XX} / \mathrm{XY}$ and $\mathrm{ZZ} / \mathrm{ZW}$ both \\
\hline & $\mathrm{XY}$-male-green & & XY female - REV & Male-only green DNA signal on female sample & "W" signal but with male DNA & so unknowns must be sex reversed. \\
\hline & & Male-producing & $\mathrm{XX}$ male - REV & Uniform yellow & & SEX CHROMOSOMES EXIST AND SEX REVERSAL PRESENT \\
\hline & & & $\mathrm{XY}$ male & Male-only green DNA signal on male sample & "Y" signal with male DNA & \\
\hline A3 & XX-female-red & Female-producing & XX female & Uniform yellow & & Unpainted chromosome indicate $X Y$ or $Z W$ could \\
\hline & XX-male-REV-green & & XY female - REV & One unpainted unpaired chromosome & "W" signal & $\begin{array}{l}\text { exist but DNA used for CGH must be only homogametic } \\
\text { so one individual is sex reversed. However, still cannot }\end{array}$ \\
\hline & & Male-producing & XX male - REV & Uniform yellow & & have $Z W$ and $X Y$ both so unknowns must be sex reversed. \\
\hline & & & $\mathrm{XY}$ male & One unpainted unpaired chromosome & "Y" signal & SEX CHROMOSOMES EXIST AND SEX REVERSAL PRESENT \\
\hline A4 & $\begin{array}{c}\mathrm{XY} \text {-female-REV-red } \\
\mathrm{XY} \text {-male-green }\end{array}$ & Female-producing & $\begin{array}{c}\text { XX female } \\
\text { XY female - REV }\end{array}$ & $\begin{array}{l}\text { Uniform yellow } \\
\text { Uniform yellow }\end{array}$ & $\begin{array}{l}\text { Lack of sex chromosomes (TSD) } \\
\text { OR ALTERNATIVELY }\end{array}$ & $\begin{array}{l}\text { Indistinguishable from TSD system } \\
\text { lacking sex chromosomes. }\end{array}$ \\
\hline & & & & & CGH DNA contains either & CGH done with multiple pairs of male/fem DNA should \\
\hline & & Male-producing & $\begin{array}{c}\mathrm{XX} \text { male }-\mathrm{REV} \\
\mathrm{XY} \text { male }\end{array}$ & $\begin{array}{l}\text { Uniform yellow } \\
\text { Uniform yellow }\end{array}$ & $\begin{array}{l}\text { XYmale\&XYfemale or } \\
\text { zWmale\&ZWfemale }\end{array}$ & $\begin{array}{l}\text { rule this out as the likelihood of all pairs being XYF/XYM } \\
\text { is negligible. If all tests give uniform yellow = TSD }\end{array}$ \\
\hline A5 & XY-female-REV-red & Female-producing & XX female & Uniform yellow & & Cannot have $\mathrm{XX} / \mathrm{XY}$ and $\mathrm{ZZ} / \mathrm{ZW}$ both \\
\hline & XX-male-REV-green & & XY female - REV & Female-only red DNA signal on female sample & "W" signal with female DNA & so unknowns must be sex reversed. \\
\hline & & Male-producing & XX male - REV & Uniform yellow & & SEX CHROMOSOMES EXIST AND SEX REVERSAL PRESENT \\
\hline & & & $\mathrm{XY}$ male & Female-only red DNA signal on male sample & "Y" signal but with female DNA & \\
\hline & & & SSUM & THE EXISTENCE OF AN ZZ/ZW SEX CHROMOSOI & SYSTEM & \\
\hline & & & Cyto \& & & & \\
\hline CASE & CGH DNA & IncTemp & Phenotypic Sex & CGH result & Suggestive of & Interpretation \\
\hline B1 & ZW-female-red & Pivotal & ZW female & Female-only red DNA signal on female sample & $\mathrm{zW}$ & ZW system - clean \\
\hline & Z2-male-green & & $2 z$ male & Uniform yellow & $\mathrm{zz}$ & SEX CHROMOSOMES ARE CLEARLY SHOWN \\
\hline B2 & ZW-female-red & Female-producing & ZZ female - REV & Uniform yellow & & Cannot have $\mathrm{XX} / \mathrm{XY}$ and $\mathrm{ZZ} / \mathrm{ZW}$ both \\
\hline & ZZ-male-green & & ZW female & Female-only red DNA signal on female sample & "W" signal with female DNA & so unknowns must be sex reversed. \\
\hline & & Male-producing & $2 z$ male & Uniform yellow & & SEX CHROMOSOMES EXIST AND SEX REVERSAL PRESENT \\
\hline & & & ZW male - REV & Female-only red DNA signal but on male sample & "Y" signal but with female DNA & \\
\hline B3 & ZZ-female-REV-red & Female-producing & $\mathrm{ZZ}$ female - REV & Uniform yellow & & Unpainted chromosome indicate $\mathrm{ZW}$ or $\mathrm{ZW}$ could \\
\hline & zZ-male-green & & ZW female & One unpainted unpaired chromosome & "W" signal & $\begin{array}{l}\text { exist but DNA used for CGH must be only homogametic } \\
\text { so one individual is sex reversed. However, still cannot }\end{array}$ \\
\hline & & Male-producing & $\mathrm{zz}$ male & Uniform yellow & & have $Z W$ and $Z W$ both so unknowns must be sex reversed. \\
\hline & & & ZW male - REV & One unpainted unpaired chromosome & "Y" signal & SEX CHROMOSOMES EXIST AND SEX REVERSAL PRESENT \\
\hline B4 & ZW-female-red & Female-producing & ZZ female - REV & Uniform yellow & Lack of sex chromosomes (TSD) & Indistinguishable from TSD system \\
\hline & ZW-male-REV-green & & ZW female & Uniform yellow & OR ALTERNATIVELY & lacking sex chromosomes. \\
\hline & & & & & CGH DNA contains either & CGH done with multiple pairs of male/fem DNA should \\
\hline & & Male-producing & $\begin{array}{c}2 Z \text { male } \\
\mathrm{ZW} \text { male - REV }\end{array}$ & $\begin{array}{l}\text { Uniform yellow } \\
\text { Uniform yellow }\end{array}$ & $\begin{array}{l}\text { XYmale\&XYfemale or } \\
\text { ZWmale\&ZWfemale }\end{array}$ & rule this out as the likelihood of all pairs being ZWF/ZWM \\
\hline B5 & ZZ-female-REV-red & Female-producing & ZZ female - REV & Uniform yellow & & Cannot have $\mathrm{XX} / \mathrm{XY}$ and $\mathrm{ZZ} / \mathrm{ZW}$ both \\
\hline & ZW-male-REV-green & & ZW female & Male-only green DNA signal on female sample & "W" signal but with male DNA & so unknowns must be sex reversed. \\
\hline & & Male-producing & ZZ male & Uniform yellow & & SEX CHROMOSOMES EXIST AND SEX REVERSAL PRESENT \\
\hline & & & ZW male - REV & Male-only green DNA signal on male sample & "Y" signal with male DNA & \\
\hline
\end{tabular}

Fig. 3. Potential CGH results given all possible scenarios of sex reversal in the individuals examined (sample) and in the individuals whose DNA was used for the hybridization (CGH DNA source).

short, fibroblast cell cultures were established from collagenase (Sigma) digests of muscle tissue and cultured in 50\% RPMI 1640 and $50 \%$ Leibowitz media supplemented with $15 \%$ fetal bovine serum, $2 \mathrm{~mm}$ L-glutamine, and 1\% antibiotic-antimycotic solution (Sigma), and incubated at $30^{\circ} \mathrm{C}$ without $\mathrm{CO}_{2}$ supplementation. Four hours before harvesting, $10 \mu \mathrm{g} / \mathrm{ml}$ colcemid (Roche) was added to the cultures. Metaphase chromosomes were harvested, fixed in 3:1 methanol:acetic acid, and cell suspensions were dropped onto glass slides and air-dried. G-banding followed standard protocols [Seabright, 1971]. Chromosomes were distinguished by morphology, size and DAPI-banding.

Male and female genomic DNA was labeled with digoxigendUTP or biotin-dUTP fluorophores using nick translation (Roche) and CGH was performed as described elsewhere [Badenhorst et al., 2013]. Namely, chromosome slides were hardened $\left(65^{\circ} \mathrm{C}\right.$ for $\left.2 \mathrm{~h}\right)$, denatured $\left(2 \mathrm{~min}\right.$ at $70^{\circ} \mathrm{C}$ in $70 \%$ formamide, $\left.2 \times \mathrm{SSC}\right)$, dehydrated (through an ethanol series), and air-dried. A $15-\mu$ l mixture per slide containing 250-500 ng of digoxigen-dUTP female and biotin-dUTP male was co-precipitated with 5-10 $\mu \mathrm{g}$ boiled genomic DNA from male or female (competitor) and $20 \mu$ glycogen (carrier), and hybridized to a slide $\left(37^{\circ} \mathrm{C}\right.$ for 3 days in a humid chamber). Slides containing chromosome spreads and probe were washed $2 \times$, first in $0.4 \times \mathrm{SSC} / 0.3 \%$ Tween 20 for $2 \mathrm{~min}$ at $60^{\circ} \mathrm{C}$, followed by $1 \mathrm{~min}$ at room temperature in $2 \times \mathrm{SSC} / 0.1 \%$ Tween 20 . A $250 \mu \mathrm{l}$ solution of $4 \mathrm{XT} /$ relevant antibody was used for fluorochrome detection at $37^{\circ} \mathrm{C}$ for $20-45 \mathrm{~min}$. Slides were washed $3 \times$ 
$\left(4 \mathrm{XT}\right.$ at $\left.37^{\circ} \mathrm{C}\right)$ and counterstained $(6 \mu \mathrm{l}$ DAPI $2 \mathrm{mg} / \mathrm{ml}$ in $50 \mathrm{ml} 2 \times$ SSC). A CCD camera attached to an Olympus BX41 fluorescence microscope was used to capture images, and Genus Imaging Software (Applied Imaging) was used for image analysis. Reciprocal experiments were conducted such that each sex-by-color combination was tested and both sexes were used as competitor. At least 10 complete metaphases were analyzed per hatchling.

Because sex-reversed hatchlings may be present among our samples, the following precautions were taken. We considered all potential CGH results, taking into account the possibility that the DNA used may come from sex-reversed individuals - as may the metaphases from the 20 males and 13 females (assuming XY or ZW sex chromosome systems) (fig. 3). After considering all possible scenarios, there is only one instance where the results between C. picta having sex chromosomes and C. picta having a pure TSD system lacking sex chromosomes would be indistinguishable. Namely, if the labeled-DNA used for the probe came from an XY female and an XY male (or ZW female and ZW male), this would generate a uniform CGH signal with both colors in all individuals, given that both the red-labeled and green-labeled DNA would contain X-DNA and Y-DNA (or Z-DNA and W-DNA) (case A4 or B4 in fig. 3). Such uniform painting would be identical to that expected under pure TSD in the absence of sex chromosomes. To rule this out, the CGH analysis was repeated 4 times, using DNA from 4 separate pairs of males and females ( 3 of which were obtained from incubation at the $28.5^{\circ} \mathrm{C}$ pivotal temperature). Since the possibility that all 4 pairs of male/female DNA would include this particular combination of sex-reversed DNA (i.e. XY females and $\mathrm{XY}$ males) is unlikely, finding uniform painting in all chromosomes of males and females would strongly suggest that sex chromosomes do not exist in C. picta that are detectable at the resolution of $\mathrm{CGH}$.

\section{Results and Discussion}

CGH has successfully detected cryptic sex chromosomes in turtles and other reptiles that were unidentifiable by classic cytogenetic techniques, including some involving microchromosomes [Ezaz et al., 2005, 2006; Martinez et al., 2008; Kawai et al., 2009; Badenhorst et al., 2013]. Chromosomal regions that are male- or femalespecific (as in $\mathrm{Y}$ or $\mathrm{W}$ chromosomes) are identified by the detection of a single color (fluorophore) in that region. However, the hybridization patterns observed in our study were consistent between males and females regardless of the DNA combination used for the CGH (fig. 2), with no genomic region exhibiting a male- or female-specific signal. As detailed in figure 3 , a mixture of staining patterns would have been expected if $C$. picta possessed an XX/XY or a ZZ/ZW system of sex chromosomes, and if some of our hatchlings or the male and female whose DNA was used for painting were sex reversed by the incubation temperature (a GSD + EE system of sex determination sensu Valenzuela et al. [2003]). The possibility that the uniform painting result was due to hybridizing both heterogametic male and female DNA (fig. 3) was ruled out by using 4 separate pairs of male and female DNA (see above). Thus, our data do not support the presence of cryptic sex chromosomes in C. picta. We can confidently conclude that our results are consistent with the presence of a pure TSD system in this species.

Our results provide the first molecular cytogenetic data consistent with the absence of sex chromosomes in painted turtles. How do we reconcile our findings with previous studies that suggest there is an underlying GSD mechanism in TSD turtles [Engel et al., 1981; Bull et al., 1982; Demas et al., 1990; Girondot et al., 1994; Rhen and Lang, 1998; Mork et al., 2014]? Several explanations are possible. First, factors other than non-additive genetic variance may explain the heritability values obtained in previous studies [e.g. Bull et al., 1982; Rhen et al., 2011]. Namely, heritability is measured as the variance in sex ratio between clutches or as the correlation in sex in sibsib comparisons [Bull et al., 1982; Rhen and Lang, 1998]. This approach assumes that maternal effects are absent and do not account for any of the observed variation among families and correlation between siblings, attributing them to additive genetic variance entirely. However, heritability measures in TSD taxa are much lower under fluctuating temperature conditions typically encountered in natural nests [Bull et al., 1982] and are also inflated by confounding factors, including dominant and epistatic genetic variance [Conover and Heins, 1987; Olsson et al., 1996; Saillant et al., 2002], nest-site effects [Shine et al., 1997], and maternal effects such as yolk hormones [Bowden et al., 2000]. Such maternal effects could also explain why embryonic gonads follow the same sexual differentiation trajectory at the pivotal temperature [Mork et al., 2014]. Second, while genetic variation for TSD is expected among individuals that would permit the evolution of TSD reaction norms (e.g. variation in embryonic responsiveness to temperature) and should be measurable as the genotype by environment $(\mathrm{G} \times \mathrm{E})$ interaction on sex ratio [Rhen et al., 2011], such heritability may not reflect an underlying GSD mechanism and should not be confused with GSD. That is, genetic variation underlying phenotypic plasticity (such as TSD) is an expected component that enables the evolution of adaptive plasticity where phenotypes develop in response to a heterogeneous environment [Via et al., 1995; Rhen et al., 2011], whereas GSD represents a canalized developmental system where the phenotypic fate is established by the genotype across all environments [Valenzuela, 2008]. Finally, it is plausible that genotypic differences exist between 
males and females in TSD turtles that are not detectable at the resolution of molecular cytogenetic techniques, which are restricted to differences greater than $\sim 3 \mathrm{Mb}$. Thus far, efforts to find small-scale genetic differences between male and females in TSD turtles have failed. For instance, previous studies identified $\mathrm{H}-\mathrm{Y}$ antigens in TSD turtles that segregated by sex in individuals incubated at the pivotal temperature [Zaborski et al., 1988]; a result that appeared promising at the time, since the H-Y antigen had been proposed as the testis-determining factor [Wachtel et al., 1975]. However, later research disproved this role for H-Y antigens [McLaren et al., 1984; Goldberg et al., 1991]. Today we know that H-Y antigens are encoded by multiple loci of the minor histocompatibility antigen (mHA) family, some of which are Y-linked in mammals and have X-linked homologues [Miklos et al., 2005], and in actuality are expressed as a consequence of sex determination and are not the cause of sex determination. This would generate a pattern of expression that segregates by sex and could be misinterpreted easily as a marker of an underlying GSD mechanism in TSD turtles [Engel et al., 1981; Girondot et al., 1994]. Additionally, the sex-specific segregation of Bkm satellite DNA in sea turtles (TSD) reported by Demas et al. [1990] has not been replicated, and attempts to identify other sex-specific markers in TSD turtles have been unsuccessful [Hernández-Echeagaray et al., 2012]. Genome sequencing should provide conclusive evidence in this regard. If such efforts uncover evidence that TSD turtles possess homomorphic sex chromosomes that differ only slightly in DNA content such that they are undetectable by the molecular cytogenetic techniques used here, it might reveal a fundamental constraint for the evolution of a full spectrum of sex determination (from pure GSD to pure TSD) [Valenzuela et al., 2003; Sarre et al., 2004] that is predicted by theoretical models [Bull, 1983]. That is, finding sex chromosomes in C. picta, an exemplar TSD species, would question whether pure TSD mechanisms do exist at all in nature, or whether those currently considered pure TSD simply await further characterization of their underlying GSD architecture. If that were the case, it would raise several key questions: What prevents the evolution of pure TSD systems (and more generally ESD) in turtles and perhaps vertebrates? Why could the establishment of the sexual fate of individuals not be triggered exclusively by an environmental factor? How would our understanding of other concepts and traits that differ between GSD and TSD systems be affected by the recognition that no pure TSD system exists (e.g. the timing of the primary sex determination during development, sexual identity at con-

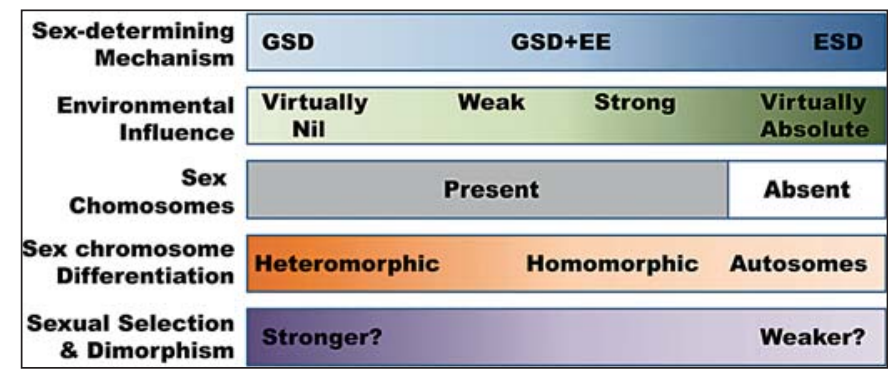

Fig. 4. The continuum of sex determination. Sex-determining mechanisms range from GSD to ESD, and the spectrum spans intermediate systems where the genotypic sex is overridden by environmental factors $(\mathrm{GSD}+\mathrm{EE})$. While the gradient of environmental influence generates a continuum, existing data supports the existence of a dichotomy within this continuum between those species lacking sex chromosomes on the one end and all others that possess sex chromosomes. Theory predicts that environmental effects on sex ratios should be stronger the less dimorphic the sex chromosomes because natural selection would oppose the production of YY and WW individuals whose fitness decreases the more heteromorphic the sex chromosomes are [Valenzuela, 2004; Bachtrog et al., 2014]. Questions remain for species at the ESD end of the continuum about what happens to all the processes fuelled by sex chromosome evolution in species where they are lacking [Rice, 1984; Valenzuela, 2010; Bachtrog et al., 2011; Kitano and Peichel, 2012]. For instance, how different are the evolutionary dynamics, extent, and ontogenetic development of sexual dimorphism when sex chromosomes are present or absent? Is sexual conflict or sexual selection weaker in the absence of sex chromosomes?

ception, primary and secondary sex ratios) [Valenzuela, $2008,2010]$ ? However, our results and the alternative explanations for the observations purportedly consistent with the existence of an underlying GSD system in TSD turtles indicate that C. picta (and, thus, possibly many other TSD taxa) exhibit a pure TSD system (where sex chromosomes are absent).

This result is also important as GSD and TSD systems affect sex ratios differently and trigger distinct evolutionary consequences, some of which are fostered in the presence of sex chromosomes, some in their absence. For instance, XY or ZW mechanisms under strict Mendelian inheritance generate 1:1 sex ratios when the costs of producing males and females are identical [Fisher, 1930]. Balanced sex ratios induce a greater effective population size, a higher population growth potential, and a reduced rate of loss of genetic variation than biased sex ratios. Contrastingly, ESD can drastically bias sex ratios potentially challenging population survival, as for TSD species under climate change [Neuwald and Valenzuela, 2011]. Further, chromosomal sex determination favors the ac- 
cumulation of male-beneficial genes in the $\mathrm{Y}$ and of female-beneficial genes in the $\mathrm{W}$, even if they harm the opposite sex [Bachtrog et al., 2011]. This happens because $Y$ (or W) genes are never expressed in females (or males), and thus, they escape natural selection. This process intensifies the development of sexual dimorphism while solving the sexual antagonism in ways that should be impossible for species lacking sex chromosomes. Fourth, sexual antagonism also favors reduced recombination between sex chromosomes, aggravating the mutation load, degeneration, and differential gene gain/loss in the $\mathrm{Y}$ and $\mathrm{W}$ compared to the $\mathrm{X}, \mathrm{Z}$ and autosomes [Wright and Mank, 2013].

In conclusion, current evidence supports the existence of a full continuum of sex determination spanning from GSD to ESD, and underscores a fundamental dichotomy within this continuum between ESD systems on one end of the spectrum versus all others that possess sex chromosomes, including those susceptible to environmental factors (GSD, GSD + EE) [Valenzuela et al., 2003] (fig. 4). Notably, the recognition of pure ESD systems does not negate the existence of intermediate mechanisms (GSD + $\mathrm{EE}$ ) or of the continuum itself (fig. 4, and see fig. 1 in Valenzuela et al. [2003]). Nor does it negate the extensive similarities in the composition of the developmental networks underlying vertebrate sexual development [Parma and Radi, 2012; Valenzuela et al., 2013]. However, the existence of a common network of genes underlying sexual development does not disprove the fundamental difference between GSD and ESD manifested by the presence/ absence of sex chromosomes. Denying this difference would negate the very nature of phenotypic plasticity, of which TSD is a textbook example. Instead, recognizing the existence of a full spectrum of sex determination highlights that some processes that are fuelled by the evolution of sex chromosomes may not occur in pure TSD species such as painted turtles [Rice, 1984; Valenzuela, 2008, 2010; Bachtrog et al., 2011; Kitano and Peichel, 2012]. Further research is still warranted to fully understand the evolution of sex determination and how profound the effects of sex chromosome evolution are for life on Earth.

\section{Acknowledgements}

We thank A. Burrett for her help during imaging. Partial funding was provided by NSF grants MCB 0815354 to N.V. and S.V. Edwards, and MCB 1244355 to N.V.

\section{References}

Bachtrog D, Kirkpatrick M, Mank JE, McDaniel SF, Pires JC, et al: Are all sex chromosomes created equal? Trends Genet 27:350-357 (2011).

- Bachtrog D, Mank JE, Peichel CL, Kirkpatrick M, Otto SP, et al: Sex determination: why so many ways of doing it? PLoS Biol 12:e1001899 (2014).

Badenhorst D, Stanyon R, Engstrom T, Valenzuela N: A ZZ/ZW microchromosome system in the spiny softshell turtle, Apalone spinifera, reveals an intriguing sex chromosome conservation in Trionychidae. Chromosome Res 21:137-147 (2013).

-Baroiller JF, Chourrout D, Fostier A, Jalabert B: Temperature and sex chromosomes govern sex ratios of the mouthbrooding cichlid fish Oreochromis niloticus. J Exp Zool 273:216223 (1995).

Bernhard R: Dinâmica populacional de Podocnemis erythrocephala, no rio Ayuanã: Programa de Pós-Graduação em Ecologia, p 106 (Instituto Nacional de Pesquisas da Amazônia INPA, Manaus, Amazonas, Brazil 2010).

Bowden RM, Ewert MA, Nelson CE: Environmental sex determination in a reptile varies seasonally and with yolk hormones. Proc Biol Sci 267:1745-1749 (2000).
Bull JJ: Evolution of sex determining mechanisms. (Benjamin Cummings, Menlo Park 1983).

Bull JJ, Vogt RC, Bulmer MG: Heritability of sex ratio in turtles with environmental sex determination. Evolution 36:333-341 (1982).

Chiari Y, Cahais V, Galtier N, Delsuc F: Phylogenomic analyses support the position of turtles as the sister group of birds and crocodiles ( $\mathrm{Ar}$ chosauria). BMC Biol 10:65 (2012).

Conover DO, Heins SW: The environmental and genetic components of sex ratio in Menidia menidia (Pisces: Atherinidae). Copeia 1987: 732-743 (1987).

-Demas S, Duronslet M, Wachtel S, Caillouet C, Nakamura D: Sex-specific DNA in reptiles with temperature sex determination. J Exp Zool 253:319-324 (1990).

De Smet WHO: Chromosomes of 22 species of Chelonia (Reptilia). Acta Zool Pathologica Antverpiensia 70:15-34 (1978).

Engel W, Klemme B, Schmid M: H-Y antigen and sex determination in turtles. Differentiation 20:152-156 (1981).

Ezaz T, Quinn AE, Miura I, Sarre SD, Georges A, Marshall Graves JA: The dragon lizard Pogona vitticeps has ZZ/ZW micro-sex chromosomes. Chromosome Res 13:763-776 (2005).
Ezaz T, Valenzuela N, Grützner F, Miura I, Georges A, et al: An XX/XY sex microchromosome system in a freshwater turtle, Chelodina longicollis (Testudines: Chelidae) with genetic sex determination. Chromosome Res 14:139-150 (2006).

Fisher RA: The genetical theory of natural selection. (Oxford University Press, Oxford 1930).

Girondot M, Zaborski P, Servan J, Pieau C: Genetic contribution to sex determination in turtles with environmental sex determination. Genet Res 63:117-127 (1994).

Goldberg EH, McLaren A, Reilly B: Male antigen defined serologically does not identify a factor responsible for testicular development. J Reprod Immunol 20:305-309 (1991).

Grützner F, Rens W, Tsend-Ayush E, El-Mogharbel N, O'Brien PC, et al: In the platypus a meiotic chain of ten sex chromosomes shares genes with the bird $\mathrm{Z}$ and mammal $\mathrm{X}$ chromosomes. Nature 432:913-917 (2004).

Hare KM, Yeong C, Cree A: Does gestational temperature or prenatal sex ratio influence development of sexual dimorphism in a viviparous skink? J Exp Zool A Ecol Genet Physiol 315: 215-221 (2011).
No Evidence of Cryptic Sex

Chromosomes in TSD Turtles
Cytogenet Genome Res 2014;144:39-46 DOI: $10.1159 / 000366076$ 
Hernández-Echeagaray OE, Hernández-Cornejo R, Harfush-Meléndez M, García-Gasca A: Evaluation of sex ratios of the olive ridley sea turtle (Lepidochelys olivacea) on the arribada nesting beach, La Escobilla, Mexico. Mar Turt Newsl 133:12-16 (2012).

Inamdar Doddamani LS, Vani V, Seshagiri PB: A tropical oviparous lizard, Calotes versicolor exhibiting a potentially novel FMFM pattern of temperature-dependent sex determination. J Exp Zool A Ecol Genet Physiol 317: 32-46 (2012).

-Janzen FJ: Heritable variation for sex ratio under environmental sex determination in the common snapping turtle (Chelydra serpentina). Genetics 131:155-161 (1992).

- Jones MEH, Anderson CL, Hipsley CA, Müller J, Evans SE, Schoch RR: Integration of molecules and new fossils supports a Triassic origin for Lepidosauria (lizards, snakes, and tuatara). BMC Evol Biol 13:208 (2013)

-Kawai A, Ishijima J, Nishida C, Kosaka A, Ota H, et al: The ZW sex chromosomes of Gekko hokouensis (Gekkonidae, Squamata) represent highly conserved homology with those of avian species. Chromosoma 118:43-51 (2009).

Killebrew FC: Mitotic chromosomes of turtles. IV. The Emydidae. Texas J Sci 29:245-253 (1977).

Kitano J, Peichel CL: Turnover of sex chromosomes and speciation in fishes. Env Biol Fish 94:549-558 (2012).

Leaché AD, Sites JW Jr: Chromosome evolution and diversification in North American spiny lizards (genus Sceloporus). Cytogenet Genome Res 127:166-181 (2009).

-Martinez P, Ezaz T, Valenzuela N, Georges A, Marshall Graves JA: An XX/XY heteromorphic sex chromosome system in the Australian chelid turtle Emydura macquarii: a new piece in the puzzle of sex chromosome evolution in turtles. Chromosome Res 16:815-825 (2008).

McGaugh SE, Janzen FJ: Effective heritability of targets of sex-ratio selection under environmental sex determination. J Evol Biol 24:784794 (2011)

McLaren A, Simpson E, Tomonari K, Chandler P, Hogg H: Male sexual differentiation in mice lacking H-Y antigen. Nature 312:552-555 (1984).

Miklos DB, Kim HT, Miller KH, Guo L, Zorn E, et al: Antibody responses to H-Y minor histocompatibility antigens correlate with chronic graft-versus-host disease and disease remission. Blood 105:2973-2978 (2005).

Mork L, Czerwinski M, Capel B: Predetermination of sexual fate in a turtle with temperature-dependent sex determination. Dev Biol 386:264-271 (2014).

Neuwald JL, Valenzuela N: The lesser known challenge of climate change: thermal variance and sex-reversal in vertebrates with temperature-dependent sex determination. PLoS One 6:e18117 (2011).

-Okada Y, Yabe T, Oda SI: Temperature-dependent sex determination in the Japanese pond turtle, Mauremys japonica (Reptilia: Geoemydidae). Curr Herpetol 29:1-10 (2010).

Olmo E: Rate of chromosome changes and speciation in reptiles. Genetica 125:185-203 (2005).

Olmo E, Signorino GG: ChromoRep: A reptiles chromosomes database, 2005.

Olsson M, Gullberg A, Shine R, Madsen T, Tegelström $\mathrm{H}$ : Paternal genotype influences incubation period, offspring size, and offspring shape in an oviparous reptile. Evolution 50: 1328-1333 (1996).

-Organ CL, Janes DE: Evolution of sex chromosomes in Sauropsida. Integr Comp Biol 48: 512-519 (2008).

- Paez VP, Correa JC, Cano AM: A comparison of maternal and temperature effects on sex, size, and growth of hatchlings of the magdalena river turtle (Podocnemis lewyana) incubated under field and controlled laboratory conditions. Copeia:698-704 (2009).

- Parma P, Radi O: Molecular mechanisms of sexual development. Sex Dev 6:7-17 (2012).

Pokorná M, Kratochvíl L: Phylogeny of sex-determining mechanisms in squamate reptiles: are sex chromosomes an evolutionary trap? Zool J Linn Soc 156:168-183 (2009).

-Quinn AE, Georges A, Sarre SD, Guarino F, Ezaz $\mathrm{T}$, Graves JA: Temperature sex reversal implies sex gene dosage in a reptile. Science 316 : 411 (2007).

Rhen T, Lang JW: Among-family variation for environmental sex determination in reptiles. Evolution 52:1514-1520 (1998).

Rhen T, Schroeder A, Sakata JT, Huang V, Crews D: Segregating variation for temperature-dependent sex determination in a lizard. Heredity 106:649-660 (2011).

-Rice WR: Sex chromosomes and the evolution of sexual dimorphism. Evolution 38:735-742 (1984).

Rojo V, Giovannotti M, Caputo V, Gonzalez-Tizon AM, Naveira $\mathrm{H}$, et al: Sex chromosome evolution in the lizard Iberolacerta monticola (Boulenger, 1905): karyological characterization of endemic Spanish populations. Chromosome Res 20:811 (2012).

Sahara K, Yoshido A, Traut W: Sex chromosome evolution in moths and butterflies. Chromosome Res 20:83-94 (2012).

-Saillant E, Fostier A, Haffray P, Menu B, Thimonier J, Chatain B: Temperature effects and genotype-temperature interactions on sex determination in the European sea bass (Dicentrarchus labrax L.). J Exp Zool 292:494-505 (2002).

-Sarre SD, Georges A, Quinn A: The ends of a continuum: genetic and temperature-dependent sex determination in reptiles. Bioessays 26 : 639-645 (2004).

-Seabright M: A rapid banding technique for human chromosomes. Lancet 2:971-972 (1971).

-Shaffer HB, Minx P, Warren DE, Shedlock AM, Thomson RC, et al: The western painted turtle genome, a model for the evolution of extreme physiological adaptations in a slowly evolving lineage. Genome Biol 14:R28 (2013).
Shibaike Y, Takahashi Y, Arikura I, Iiizumi R, Kitakawa S, et al: Chromosome evolution in the lizard genus Gekko (Gekkonidae, Squamata, Reptilia) in the East Asian islands. Cytogenet Genome Res 127:182-190 (2009).

-Shine R, Elphick, MJ, Harlow PS: The influence of natural incubation environments on the phenotypic traits of hatchling lizards. Ecology 78: 2559-2568 (1997).

- Shine R, Elphick MJ, Donnellan S: Co-occurrence of multiple, supposedly incompatible modes of sex determination in a lizard population. Ecol Lett 5:486-489 (2002).

- Tang XL, Yue F,Yan XF, Zhang DJ, Xin Y, et al: Effects of gestation temperature on offspring sex and maternal reproduction in a viviparous lizard (Eremias multiocellata) living at high altitude. J Thermal Biol 37:438-444 (2012).

Valenzuela N: Evolution and maintenance of temperature-dependent sex determination, in Valenzuela N, Lance VA (eds): Temperature-Dependent Sex Determination in Vertebrates, pp 131-147 (Smithsonian Books, Washington, DC 2004).

-Valenzuela N: Sexual development and the evolution of sex determination. Sex Dev 2:64-72 (2008).

Valenzuela N: Co-evolution of genomic structure and selective forces underlying sexual development and reproduction. Cytogenet $\mathrm{Ge}$ nome Res 127:232-241 (2010).

-Valenzuela N, Adams DC: Chromosome number and sex determination co-evolve in turtles Evolution 65 1808-1813 (2011).

Valenzuela N, Lance VA (eds): Temperature-Dependent Sex Determination in Vertebrates. (Smithsonian Books, Washington, DC 2004).

-Valenzuela N, Adams DC, Janzen FJ: Pattern does not equal process: exactly when is sex environmentally determined? Am Nat 161:676683 (2003).

Valenzuela N, Neuwald J, Literman R: Transcriptional evolution underlying vertebrate sexual development. Dev Dyn 242:307-319 (2013).

Via S, Gomulkiewicz R, De Jong G, Scheiner SM Schlichting CD, Van Tienderen PH: Adaptive phenotypic plasticity: consensus and controversy. Trends Ecol Evol 10:212-217 (1995).

Vogt RC: Amazon Turtles. (Grafica biblos, Lima 2008).

Wachtel SS, Ono S, Koo GC, Boyse EA: Possible role for $\mathrm{H}-\mathrm{Y}$ antigen in primary determination of sex. Nature 257:235-236 (1975).

-Wright AE, Mank JE: The scope and strength of sex-specific selection in genome evolution. J Evol Biol 26:1841-1853 (2013).

Zaborski P, Dorizzi M, Pieau C: Temperature-dependent gonadal differentiation in the turtle Emys orbicularis: concordance between sexual phenotype and serological H-Y antigen expression at threshold temperature. Differentiation 38:17-20 (1988).

Zhang DJ, Tang XL, Yue F, Chen Z, Li RD, Chen Q: Effect of gestation temperature on sexual and morphological phenotypes of offspring in a viviparous lizard, Eremias multiocellata. J Thermal Biol 35:129-133 (2010). 